between paediatric patients and their parent. A process evaluation will provide more information about the underlying mechanisms of the intervention.

\section{P69 DEVELOPMENT AND EVALUATION OF AN ACP-PROGRAM FOR PROFESSIONALS IN PALLIATIVE CARE FOR PEOPLE WITH INTELLECTUAL DISABILITIES}

${ }^{1}$ AGFM Vogel ${ }^{*},{ }^{1,2,3}$ AMA Wagemans, ${ }^{4} \mathrm{H}$ Voss, ${ }^{4,5,6} \mathrm{AL}$ Francke, ${ }^{3} \mathrm{JFM}$ Metsemakers, ${ }^{2} \mathrm{AM}$ Courtens, ${ }^{4} \mathrm{AJE}$ de Veer. 'Maasveld, Koraal, Maastricht, Netherlands; ${ }^{2}$ Expertise Centre for Palliative Care, Maastricht University Medical Centre, Maastricht, the Netherlands; ${ }^{3}$ Department of Family Medicine, Faculty of Health, Medicine and Life Science, Maastricht University, the Netherlands; ${ }^{4}$ Netherlands Institute of Health Services Research (NIVEL), Utrecht, the Netherlands; ${ }^{5}$ Amsterdam UMC, VU Amsterdam, Amsterdam Public Health research institute, the Netherlands; ${ }^{6}$ Expertise Center for Palliative Care Amsterdam, Amsterdam UMC, location VU, Amsterdam, the Netherlands

\subsection{6/spcare-2019-ACPICONGRESSABS.150}

Background People with intellectual disabilities (ID) have restricted cognitive and communicative abilities, and therefore encounter difficulties in clarifying their wishes and needs. Professionals in ID-care do not always recognize palliative care needs and lack communication skills to talk about future care in advance. Aim of this study was to develop and evaluate an advance care planning (ACP)-program to train professionals in knowledge and skills about ACP in palliative care for people with ID.

Methods This study contained five phases. Phase 1 consisted of a systematic review, (medical)file analysis and supplementary interviews, and depth-interviews to discover important aspects of ACP. These were translated into an ACP-program in co-creation with professionals, relatives and people with ID (phase 2). A communication training framework was developed (phase 3). Implementation of the ACP-program took place in six organizations providing ID-care (phase 4). In phase 5 the program was evaluated by pre-structured questionnaires send to participants of the program.

Results The ACP-program consists of 1.Methodology about important aspects of ACP, 2.ACP communication training, and 3.Consultation about implementation strategies for ACP. It is based on 10 competencies needed for ACP; palliative phase identification, signaling symptoms, communicating, documenting, structurally deploying ACP, taking wishes of people with ID into account, collaborating, paying attention to possible dilemmas, reflecting, and regarding $\mathrm{ACP}$ as a standard aspect of palliative care.

Conclusion An ACP program is helpful to make professionals aware of the importance of ACP and improve communication skills. Research is needed to further investigate the effective elements of the ACP program.

\section{P70 EFFECTS OF AN ADVANCE CARE PLANNING EDUCATIONAL PROGRAM INTERVENTION IN AN ACUTE HOSPITAL; A QUALITATIVE DATA ANALYSIS}

${ }^{1} \mathrm{M}$ Hamayoshi* ${ }^{2} \mathrm{~S}$ Goto, ${ }^{3} \mathrm{~A}$ Kono, ${ }^{1} \mathrm{C}$ Matsuoka, ${ }^{4} \mathrm{M}$ Ikenaga. ${ }^{1}$ Bukkyo University, Kyoto, Japan; ${ }^{2}$ Konan womans university, Kobe City, Japan; ${ }^{3}$ Osaka city university, Osaka, Japan; ${ }^{4}$ Yodogawa Christian hospital, Osaka, Japan

10.1136/spcare-2019-ACPICONGRESSABS.151

Background Advance care planning (ACP) is a crucial end-oflife care practice. However, an ACP educational program for practitioners in an acute care setting has not yet been established. This study aimed to examine the effects of an ACP educational program in acute hospital. Aim: This work is evaluating the effect of ACP education programme on acute hospital practitioners. Design: A mixed-methods, Pre-and post test study to evaluate changing practitioner attitudes post program. The intervention program was three times during the 3 month in 90 minutes per session. As a program evaluation, comments on participant's questionnaires two questions about an attitude and practice were categorized and evaluated. We used conventional content analysis. Setting/Participants: The final sample of 63 practitioners whose they were working at B acute hospital.

Results As a result of analysis of qualitative data, Question1 was categorized into five categories, and Question2 was categorized into seven categories. The results that participants thought important of ACP implementation and talk with patient and family. It was suggested that participants were able to look back on their own way of thinking about death and found the tips of ACP implementation.

Conclusion The key message of this study was change sustained of awareness about positive attitude of ACP and EOL after 6 month intervention. These results suggest that the present ACP educational program was effective at improving staff attitudes towards the end of life care of patients.

\section{P72 TRANSLATION INTO SPANISH, CROSS-CULTURAL ADAPTATION AND VALIDATION OF AN ADVANCE CARE PLANNING SELF-EFFICACY SCALE: PRELIMINARY RESULTS}

${ }^{1} \mathrm{C}$ Lasmarias*, ${ }^{1} \mathrm{~A}$ Aradilla-Herrero, ${ }^{2} \mathrm{M}$ Subirana-Casacuberta, ${ }^{2} \mathrm{~S}$ Ela, ${ }^{3} \mathrm{~S}$ Delgado, ${ }^{4} X$ Gómez-Batiste. ${ }^{1}$ Chair of Palliative Care, Barcelona, El Salvador; ${ }^{2}$ Consorci Hospitalari de Vic, Vic, Spain; ${ }^{3}$ St Luke's Hospice, London, UK; ${ }^{4}$ University of Vic, Vic, Spain

\subsection{6/spcare-2019-ACPICONGRESSABS.152}

Background Advance Care Planning (ACP) explores patients' values and preferences to plan their care. Barriers for healthcare professionals to start it include fear to talk about end of life or lack of communication skills. Self-efficacy (SE) is a key factor that impacts learning about ACP. Measuring SE would show the impact of training to acquire ACP competencies. The ACP SE scale (ACP_SEs) of 17 items was validated in 2017; there aren't similar validated tools in Spanish.

Methods The ACP SEs was forward-backward translated. 10 ACP local experts tested it for clarity and comprehensibility. Validation: we designed a survey with 4 dimensions: sociodemographic variables; knowledge and self-perception on ACP; type of patients attended; 4 scales to predictive validity: ACP_SEs (Baughman, 2017); Trait Meta-Mood_s 24 (Salovey and Mayer, 1995); Personal Competence_s (Wallston, 1992); Coping with Death_s (Bugen, 1980). Participants: 5,500 professionals from 4 scientific societies: Palliative and Primary Care (3 societies); Geriatrics/Gerontologic (1society). Reliability will be determined by intraclass correlation coefficients, the measurement will be compared by T'Student and internal consistency by Cronbach's $\alpha$. Test-retest reliability will be quantified with a 4-week interval.

Results After the translation/adaptation process, the ACP_SEs has 19 items. New variables include to involve patients in $\overline{A C P}$ and to register ACP adequately. In a pilot with 47 professionals, consistency was $\alpha=0.909$. The results will confirm the scale's validity and show how professionals rate the ACP process. 
Conclusion A validated ACP_SEs in Spanish will allow measuring the impact of training programs designed to implement ACP in the Spanish-speaking context.

\section{P74 ADVANCE CARE PLANNING AND END OF LIFE CARE FOR PATIENTS WITH HUNTINGTON'S DISEASE: A QUALITATIVE STUDY DESIGN}

${ }^{1} \mathrm{M}$ Ekkel ${ }^{*},{ }^{2} \mathrm{E}$ Verschuur, ${ }^{1} \mathrm{M}$ Depla, ${ }^{1} \mathrm{R}$ Veenhuizen, ${ }^{1} \mathrm{~B}$ Onwuteaka-Philipsen, ${ }^{1} \mathrm{C}$ Hertogh. ${ }^{1} \mathrm{VU}$ University Medical Center, Amsterdam, Netherlands; ${ }^{2}$ HAN University of Applied Sciences, Nijmegen, Netherlands

\subsection{6/spcare-2019-ACPICONGRESSABS. 153}

Background Huntington's disease (HD) is an inherited neurodegenerative disease, characterized by movement disorders, psychiatric symptoms, and cognitive decline. In the later stages of the disease patients often are no longer able to express their wishes for care, because of problems with communication and cognitive decline. Little is known about advance care planning, advance directives, and end of life care for HD patients.

Aims: In this study we aim to explore HD patients' perceptions of their future, end of life, and end of life care, and whether these perceptions change over time. Furthermore, we aim to study the views of elderly care physicians on advance care planning and end of life care for HD patients.

Methods A qualitative approach is adopted using semi-structured interviews. Approximately 10-15 HD patients will be interviewed every 6 months for a period of 2 to 2.5 years. Topics are: quality of life, the future, end of life, death, advance directives and talking to others about these subjects. In addition, approximately 10 elderly care physicians will be interviewed once. The physicians will be encouraged to describe their experiences with advance care planning, end of life care, patients' decision making capacity, advance directives, and euthanasia in HD. All interviews will be audio recorded and transcribed verbatim. Atlas.ti will be used for analysis.

Results and conclusions Data collection started in 2017 and results are expected in 2020. The results of this study will provide valuable information on advance care planning and end of life care for HD patients.

\section{P75 SHARED CARE PLANNING, THE TWIST THAT COULD SAVE THE UNFULFILLED POTENTIAL OF ADVANCE CARE PLANNING IN SPAIN}

${ }^{1} \mathrm{~J}$ Júdez*, ${ }^{2} \mathrm{C}$ Lasmarias, ${ }^{3} \mathrm{I}$ Saralegui, ${ }^{4} \mathrm{~N}$ Pérez de Lucas, ${ }^{5} \mathrm{H}$ García-Llana, ${ }^{6} \mathrm{~J}$ FernándezBueno, ${ }^{7} \mathrm{~N}$ Granero-Moya, ${ }^{8} \mathrm{~T}$ Velasco, ${ }^{9} \mathrm{~V}$ Carrero. ${ }^{1}$ Asociación de Bioética Fundamental y Clínica, Madrid, Spain; '2University of Vic-Central University of Catalonia, Vic, Barcelona, Spain; ${ }^{3}$ Organización Sanitaria Integrada Araba, Vitoria, Spain; ${ }^{4}$ Servicio Madrileño de Salud, Sermas, Madrid, Spain; ${ }^{5}$ Hospital Universitario La Paz, IdiPAZ, Sermas, Madrid, Spain; ${ }^{6}$ Hospital Universitario de La Princesa, Sermas, Madrid, Spain; ${ }^{7}$ Servicio Andaluz de Salud, Baeza, Jaén, Spain; ${ }^{8}$ Hospital Clínico Universitario San Carlos, Sermas, Madrid, Spain; ${ }^{9}$ Universidad Jaume I, Castellón, Spain

\subsection{6/spcare-2019-ACPICONGRESSABS. 154}

Background The "right to grant and register an advance directive" has spread in Spain's health care legislation. Reality check: documents are completed by less than $1 \%$ of the population. Having ACP philosophy widespread elsewhere, this seems a rather meager approach that, additionally, does not sympathize with the way, we, human beings suffer, endure and face illness.
Method Intellectual journey, rationale and roadmap for a new twist in Spain's theoretical, ethical and policy development.

Results Few healthcare administrations and some individual experiences in Spain are promoting ACP implementation into public health care systems. In 2017, the "Spanish Working Group on Shared Care Planning" (GET-PCA in Spanish) was build up with the conviction that what could be done to take advantage of our strengths as a National Health System and a caring Mediterranean culture was midwifing shared-decision making (SDM) for current care together with the pursue of ACP for future care in what we named as "shared care planning” (SCP).

GET-PCA defines SCP as "a deliberative, relational and structured process that facilitates reflection and understanding of illness' and care's experiences, among all involved, focusing on each person facing a disease trajectory, to identify and express their preferences and expectations within their context of care. Its goal is to promote SDM in relation to current context and ACP to future care challenges, such as when the person might not be competent to decide for herself."

Conclusion SMD matching ACP may save the day for Spain. Best of both worlds: welcome shared care planning!

\section{P76 PREPAREDEM: HELPING PEOPLE WITH DEMENTIA AND THEIR CARERS PREPARE FOR CARE IN ADVANCED ILLNESS AND END OF LIFE}

J Dixon*. London School of Economics and Political Science, London, UK

\subsection{6/spcare-2019-ACPICONGRESSABS.155}

Background The number of people living with dementia is expected to double by 2050. Experiences in advanced illness and at end of life for people with dementia and their carers can be poor. Advance care planning (ACP) is especially challenging in dementia. In this study we will explore how people with dementia and their carers prepare for advanced illness and end of life. Using quantitative and qualitative data, we will look at what factors influence them. We will ask about their experiences, including of advance care planning or other support. We will especially consider how people with dementia and their carers interact and influence each other, and what expectations they have of each other. We will also examine whether preparing, through ACP or other means, makes a difference to end of life outcomes and experiences.

Methods Secondary analysis of data from the Improving the Experience of Dementia and Enhancing Active Life (IDEAL) study (gathered from a cohort of 1500 people with dementia and their carers).

- Qualitative interviews with 40-50 carers (and people with dementia where capacity allows) taking part in the DETERMinants of quality of life, care and costs, and consequences of INequalities in people with Dementia and their family carers (DETERMIND) study (a cohort of 900 people with dementia and their carers)

- Bereavement survey with carers from the DETERMIND study who are bereaved during the course of our study (2018-2023)

Results Findings will be reported over the course of the study in academic papers, blog-posts and at a range of conferences and meetings. We will also produce guidance for policy-makers and practitioners and a short film. 